\title{
Finalidade ou linguagem: abordagens para o sentido da ação nos estudos organizacionais
}

\author{
Yeda Swirski de Souza *
}

\section{Resumo}

Este artigo pretende explicitar diferentes concepções de ação e decisão nos estudos organizacionais, recorrendo a dois caminhos teóricos. 0 primeiro está baseado em referências a Weber e a Habermas e suas diferentes proposições quanto à ação humana. 0 segundo consiste em observações sobre a evolução do conceito de processo decisório a partir de Simon. 0 argumento é 0 de que esses dois caminhos teóricos apontam para uma mesma mudança nas concepções de ação e decisão. Da ação justificada pela finalidade e realizada por um ator racional passa-se para uma concepção de ação tributária, de um sentido social e coletivamente construído, realizada por um sujeito constituído através das redes de significado que marcam sua trajetória pessoal e social.

Palavras-chave: processo decisório; ação comunicativa; limites da racionalidade; produção de sentido; sujeito da ação.

\begin{abstract}
Philosophical basis for decision and action understanding are presented at this paper. Two different theoretical approaches are investigated. One of them explore the differences between Weber and Habermas propositions about human action. The other one presents remarks about decision process concept since Simon. The purpose of the article is to underline that both approaches shows a similar change on action and decision conceptions. The rational action and decision conception gives place to a social constructed action conception. The rational actor view gives place to a self constitution based on networks of sense view.
\end{abstract}

Keywords: decision process; limited rationality; communicative action; sensemaking; social actor.

\section{Introdução}

"Uma das coisas que quase todo mundo conhece, mas não sabe muito bem como demonstrar é que a política de um país reflete o modelo de sua cultura (...) a cultura, aqui, não são cultos e costumes, mas as estruturas de significado através das quais os homens dão forma à sua experiência, e a política não são golpes e constituições, mas uma das principais arenas na qual tais estruturas se desenrolam publicamente" (GEERTZ, 1989, p.206-207).

A importância que hoje se confere à cultura e às aprendizagens sociais para compreender e desenvolver processos organizacionais sugere um modo de pensar com relação ao sentido da ação. Esse modo de pensar, associado à episteme de um sistema sociocultural, nem sempre é explícito nos estudos organizacionais. Todavia, sabe-se que hoje a ação é concebida em bases distintas daquelas que alicerçam os princípios e práticas da administração tradicional.

O propósito deste artigo é o buscar explicitar as concepções quanto ao sentido da ação e sua expressão nos estudos organizacionais. Para isso, são percorridos dois caminhos teóricos. O primeiro está baseado em referências a Weber e a Habermas, e suas diferentes proposições quanto à ação humana. O segundo consiste em um exame da evolução do conceito de processo decisório a partir de Simon.

Esses dois caminhos teóricos, embora paralelos, convergem ao permitirem descrever uma transformação nas concepções sobre a ação humana. De Weber a Habermas, é traçado um caminho desde a consciência de um

\footnotetext{
* Professora e pesquisadora da UNISINOS. Doutora em Psicologia pela PUC-RS. Mestre em Administração pela PPGA/UFRGS. Psicanalista.

E-mail: yedasou@ portoweb.com.br.

Artigo recebido em dezembro de 2003 e aceito em fevereiro de 2004.
} 
ator solitário até a racionalidade que depende do uso social da palavra. Dos trabalhos iniciais de Simon às abordagens mais contemporâneas ao problema da decisão, há um caminho que parte da noção de racionalidade limitada e que alcança a preocupação com a compreensão dos processos de produção de sentido.

Por um lado, para o que se costuma considerar como administração tradicional, identifica-se uma concepção de ação cujo sentido se justifica em sua finalidade, sendo o agente um ator racional. Por outro lado, a complexidade dos processos organizacionais, o acúmulo de informação, a dimensão cultural e axiológica e as condições de aprendizagem convocam novas concepções para a ação. A ação como efeito de sentidos socialmente construídos - sendo o agente um sujeito, singular ou coletivo, emaranhado numa teia de significados culturais - emerge como noção mais explicativa para os processos organizacionais.

Esse são os argumentos aqui desenvolvidos. Na primeira seção do artigo, apresentamos a discussão sobre o sentido da ação em Weber e Habermas. Essa discussão tem como foco o sujeito da ação. Quem é o sujeito que toma decisões? Como se constitui? Na segunda seção, destacamos etapas na evolução recente da teoria da ação, tomando como ponto de partida a revisão da abordagem clássica para a decisão empreendida por Herbert Simon. Que representações da realidade são levadas em conta em processos de decisão? Como essas representações são elaboradas, sintetizadas e convertidas em ações? Os efeitos que os argumentos aqui desenvolvidos têm para os estudos organizacionais são objeto das considerações finais deste artigo.

\section{O sentido da ação: da finalidade à palavra ou de Weber a Habermas}

A questão da compreensão do sentido da ação no campo social remonta a Max Weber, que estabeleceu as bases para os estudos da sociologia compreensiva ou interpretativa.

Para Weber, a questão é compreender a realidade social e não apenas conferir-lhe explicações causais gerais. Trata-se de completar as explicações causais com a compreensão, isto é, com o acesso às razões e motivos que levam as pessoas a agir, bem como com a interpretação do sentido que as pessoas conferem a seus atos (AKTOUF, 1989).

Segundo Habermas (1995, v.1, cap.3, p.279), a introdução que Weber faz do sentido como um conceito básico da teoria da ação ajuda a distingui-la do comportamento observável. O comportamento - seja ele externo ou interno, atividade, omissão ou aquiescência - adquire o caráter de ação se o ator associa um sentido subjetivo ao mesmo.

O compreensivismo de Max Weber se estabelece a partir da determinação de categorias que explicam os fenômenos sociais. Weber elabora não só a categoria dos tipos ideais de organização, como também os modelos conceituais das atividades sociais, das éticas e da dominação, o que muito sucintamente pode ser expresso no quadro 1 : 


\section{Quadro 1}

As categorias sociais de Weber

\section{Quatro tipos de ação}

- racional em finalidade: quando há busca de bases para uma compreensão adequada meios-finsconseqüências;

- racional em valor: baseada numa crença pessoal profunda, sem consideração pelas chances de sucesso e suas consequiências;

- afetiva: atividade baseada num impulso emocional ou passional:

- tradicional: baseada no hábito, sobre "aquilo que se faz", na simples obediência ao costume.

\section{Dois tipos de éticas}

- a ética de convicção: a ação é guiada e motivada por uma convicção ou por uma idéia colocada acima de tudo, tal como revolução, honra, fé, "o bem";

- a ética de responsabilidade: a ação é motivada e guiada por uma escolha racional e refletida, um discernimento entre o que é realista ou não, conforme os meios disponíveis ou não, conduzindo a consequiências que se pode assumir ou não.

\section{Três tipos de dominação}

- tradicional: o poder é legítimo a partir dos costumes estabelecidos e aceitos, da tradição que designa as pessoas em posição de dominação;

- legal: o poder existente é legitimado por força da lei, da regulamentação racional estabelecida;

- carismática: o poder é legitimado a partir do brilho pessoal da pessoa que o exerce, da atração e devoção que desperta e graças a seu valor, seus dons, suas qualidades excepcionais.

Fonte: adaptado a partir de Aktouf (1989, p.90).

A idéia de orientação para algum fim é essencial no sistema weberiano, sendo que a explicação para o sentido da ação é associada àquilo que a motiva. A ação racional em finalidade é considerada como a forma mais desenvolvida de ação. É ela que assegura à ação, sua máxima inteligibilidade, permitindo inscrevê-la numa causalidade histórica. Há no sistema weberiano uma circularidade que faz com que as conseqüências da ação isto é, seus fins - sejam tomados como sua causa (sua motivação), ficando num mesmo plano os motivos da ação e seus efeitos. Desse modo, o sentido da ação deve ser percebido a partir de seus fins (PHARO, 1993).

Os estudos de Weber são incorporados às análises da ação organizacional, mas apenas de modo fragmentário e parcial. Suas idéias no campo organizacional se confundem com as abordagens mais tradicionais dos estudos organizacionais, plenas de idéias modernas e iluministas que procuram colocar o indivíduo, sua capacidade de racionalidade e a ciência positiva no centro dos acontecimentos. Uma vez que Weber estabelece como tipos ideais a racionalidade, a ética da responsabilidade e a dominação legal, pode-se deduzir o comprometimento entre suas idéias e as bases da administração tradicional. As abordagens da administração conhecidas como tradicionais ou clássicas propõem que a ação organizacional pode ser planejada e executada segundo padrões estabelecidos de racionalidade.

McCarthy (1992, p.38), quando apresenta as críticas de Habermas à razão instrumental, afirma que Weber, com o conceito de racionalização, trata de captar todo um complexo de tendências relacionadas com o progresso técnico e científico e com seus efeitos sobre a trama institucional das sociedades tradicionais. Tais tendências incluem as áreas da sociedade sujeitas aos critérios da decisão racional - como a atividade econômica, o direito civil e a autoridade burocrática -, o progresso da industrialização e as conseqüências desse progresso - como o surgimento do estilo vida urbano -, a burocratização da administração e a expansão do controle burocrático, a radical desvalorização da tradição, bem como a progressiva secularização e desencantamento do mundo.

As organizações modernas e as idéias mais tradicionais da administração são de modo evidente tributárias e agentes da racionalidade analisada e descrita por Weber, quando se baseiam em uma concepção de indivíduo agindo em função da finalidade única de maximizar seus ganhos pessoais. 
Se, por um lado, desde o ponto de vista da crítica social, a racionalidade moderna foi identificada como instrumental e capaz de colocar o homem em condição permanente de servidão às estruturas burocráticas incluindo-se aí as organizações -, por outro lado, desde o ponto de vista da compreensão dos processos subjacentes à ação, a racionalidade jamais pode cumprir de modo pleno um papel explicativo. Embora participante do ideário moderno, a ação organizacional propriamente dita nunca consegue cumprir este ideário pois, de um modo ou de outro, as dimensões sociais, subjetivas ou culturais vêm concorrer com as iniciativas de conformidade da ação com o planejamento técnico e racional. Assim, a racionalidade não cumpre um papel explicativo pleno para o sentido da ação.

A ação organizacional precisa ser compreendida sobre bases distintas para que ganhem lugar as dimensões não consideradas quando se atribui à ação um sentido exclusivo de finalidade. Dessa perspectiva, a crítica que Habermas desenvolve com relação ao conceito weberiano de racionalidade abre caminhos para um maior entendimento da questão do sentido da ação no contexto das organizações.

Uma das críticas às proposições de Weber é a de que a compreensão das relações e estruturas sociais está associada, em última instância, à ação do indivíduo e a seus atos de consciência no mundo social. Habermas (1995, v.1, cap.3, p.276) afirma que a teoria do sentido em Weber é, sobretudo, uma teoria da consciência:

"Ele [Weber] não elucida sentido em conexão com o modelo discursivo; ele não o relaciona às possibilidades de compreensão através das mediações lingüísticas, mas às crenças e intenções de um sujeito ativo. Considerado, em princípio, de modo isolado (...) o que conta fundamentalmente não são as relações interpessoais entre, ao menos, dois sujeitos ativos e falantes - a relação que faria referência a buscar entendimento na linguagem - mas a atividade intencional de um sujeito solitário ativo".

Habermas - representante da Escola de Frankfurt - partilha da crítica que considera a razão instrumental, manifestada na técnica e na ciência, como uma traição do ideal iluminista emancipador. Buscando dissociar a racionalidade de uma teoria da consciência, Habermas estabelece novas bases para uma reflexão sobre a ação e seu sentido. Desenvolve uma teoria da ação, diferente da de Weber, que considera o sujeito social, em interação, ou seja, a intersubjetividade dos sujeitos numa reciprocidade dialógica que reúne o "eu"e o "tu" em torno de expectativas comuns (FREITAG, 1993; PIZZI, 1994). Para tanto, Habermas busca reconstruir as condições universais (competência comunicativa) para a produção de enunciados. Segundo Freitag e Rouanet (1993):

"(...) na situação de fala entre dois interlocutores, Ego só consegue se comunicar com Alter sobre conteúdos específicos no momento em que cria, ao mesmo tempo, pelo uso de determinados verbos, uma intersubjetividade específica, em cujo quadro esses conteúdos são transmitidos e compreendidos. A mesma sentença $p$ tem um sentido intersubjetivo (pragmático) distinto, conforme seja enunciada sob forma de promessa, de ordem, de afirmação etc. ... "(p.17).

Além disso, a transmissão de conteúdos proposicionais depende de certas condições pragmáticas. Ainda segundo Freitag e Rouanet (1993):

“(...) Em cada situação de fala existem quatro expectativas de validade (Geltungsansprüche): a de que os conteúdos transmitidos são compreensíveis, a de que os interlocutores são verazes, a de que os conteúdos proposicionais são verdadeiros, a de que o locutor, ao praticar o ato lingüístico em questão (afirmando, prometendo, ordenando), tinha razões válidas para fazê-lo, isto é, agia de acordo com normas que lhe pareciam justificadas. A interação espontânea é estável quando existe um consenso com relação a essas quatro expectativas de validade. Esse consenso é perturbado quando qualquer delas é contestada de uma forma fundamental" (p.18).

A contestação das expectativas de validade ocorre no próprio contexto da interação ou, quando se trata do conteúdo proposicional, num plano do discurso: 
"(...) A afirmação é considerada verdadeira (ou falsa) quando o discurso teórico conduzir a um consenso quanto à sua verdade ou falsidade; a norma é considerada legítima (ou ilegítima) quando o discurso prático desembocar num consenso quanto a tal legitimidade ou ilegitimidade" (op. cit., p.18).

Com Habermas, rompe-se a idéia de que apenas as proposições descritivas são passíveis de validação. Também tornam-se validáveis as proposições prescritivas ou relativas a valores. Mais uma vez, conforme Freitag e Rouanet (1993):

“(...) a teoria consensual de Habermas pretende elevar tais questões à dignidade da Wahrheitsfähigkeit (literalmente, capacidade de serem verdadeiras), mostrando como a lógica do discurso prático, no qual são debatidas, é idêntica à lógica do discurso teórico, no qual são debatidas as proposições descritivas" (p.19).

A proposição de Habermas resulta numa "situação de fala ideal", que pode ser tomada como critério de argumentação discursiva porque implica uma distribuição simétrica de chances de escolha de realização de atos de fala, em relação aos quais se supõe não existir nenhum elemento de coação, a não ser a coação do melhor argumento. Trata-se, grosso modo, do estabelecimento de condições ideais para as interações através da fala, na qual participam sujeitos emancipados, livres de qualquer coação, seja ela interna (neurose ou falsa consciência) ou externa, e que tenham como propósito a verdade, a liberdade, a justiça e a reciprocidade. Como contrapartida de uma "situação de fala ideal", define-se também um modelo de "ação comunicativa pura" (SIEBENEICHLER,1990; FREITAG e ROUANET,1993).

Na proposição da "teoria da ação comunicativa", Habermas (1995, v.1, cap.1, p.85-86) analisa quatro conceitos de ação que são correntes nas teorias sociais. Considera que a profusão de conceitos de ação empregados nas teorias sociais podem ser diferenciados, essencialmente, em quatro conceitos analiticamente distinguíveis:

- conceito de ação teleológica: que está no centro da teoria filosófica da ação desde Aristóteles. O ator visa a um fim ou estabelece a ocorrência de um estado desejado, escolhendo os meios que se revelam adequados para alcançar tal situação, aplicando-os da maneira adequada. O conceito central é o de "decisão" entre possibilidades alternativas de ação, visando a realização de um fim, guiado por princípios morais e baseado na interpretação da situação. O modelo teleológico da ação é expandido em um modelo "estratégico", quando a antecipação de decisões de parte ou ao menos uma ação orientada para a meta entram no cálculo do sucesso. Esse modelo é freqüentemente interpretado em termos utilitaristas. Espera-se que o ator escolha e calcule meios e fins do ponto de vista da maximização da utilidade ou das expectativas de utilidade. É esse modelo de ação que está subjacente às abordagens da teoria da decisão e da teoria dos jogos na economia, sociologia e teoria das organizações.

- conceito de ação normativamente regulada: não se refere ao comportamento solitário do ator entre outros atores em seus ambientes, mas a membros do grupo social que orientam sua ação segundo valores comuns. $\mathrm{O}$ ator individual se submete (ou viola) à norma quando numa determinada situação estão dadas as condições às quais a norma se aplica. As normas expressam o acordo obtido em determinado grupo social. Todos os membros de um grupo, para o qual uma determinada norma tem validade, podem esperar uns dos outros que, em dadas situações, as ações recomendadas (ou condenadas) serão realizadas (ou haverá abstinência quanto às mesmas). $\mathrm{O}$ conceito central de "submissão à norma" significa preencher uma expectativa generalizada de comportamento. Isso não tem o sentido de se esperar a realização de um evento previsto, mas o sentido normativo de que os membros estão autorizados a esperar um determinado comportamento. Esse modelo normativo da ação está pressuposto na teoria dos papéis, largamente disseminada na sociologia e na psicologia social.

- conceito de ação como encenação: não se refere ao ator isolado, nem ao grupo social, mas aos participantes em interação, representando alternativamente ator e público, público perante o qual cada um apresenta a si mesmo. $\mathrm{O}$ ator evoca em seu público uma certa imagem, uma impressão de si mesmo, através de um "desvendamento" de sua subjetividade. Cada agente pode controlar o acesso público ao sistema de suas próprias intenções, pensamentos, atitudes, desejos, sentimentos, enfim, aos diferentes aspectos aos quais 
somente o ator tem acesso privilegiado. $\mathrm{Na}$ ação como encenação, os participantes fazem uso disso e orientam suas interações através de regulações recíprocas de acesso à subjetividade. Assim, o conceito de apresentação de si não significa o comportamento espontâneo expressivo, mas a estilização que se pode fazer da própria experiência, tendo em vista uma audiência. O modelo de encenação da ação é utilizado nas descrições fenomenológicas da interação, consagrando-se nos escritos de Goffman;1

- conceito de ação comunicativa: refere-se à interação de pelo menos dois sujeitos capazes de palavra e ação, os quais estabelecem relações interpessoais (através de meios verbais ou não verbais). Os atores buscam alcançar entendimento sobre a situação de ação e seus planos de ação, tendo em vista o acordo quanto à coordenação de ações. O conceito central de interpretação se refere, em primeira instância, à negociação de definições da situação, admitidas por consenso. A linguagem tem um lugar proeminente nesse modelo.

Em uma reflexão sobre o sentido da ação do contexto organizacional é evidente que pouco contribui o estabelecimento de mais um "modelo ideal" a ser tomado como prescritivo, a exemplo da "racionalidade em finalidade". No entanto, por um lado, em Habermas a "situação lingüística ideal" e a "ação comunicativa pura" podem ser tomadas apenas como modelos contrafáticos e utópicos. Por outro lado, a proposição de retirar a racionalidade do reduto da consciência para buscar suas articulações no campo do uso social da palavra possibilita uma releitura dos problemas concernentes à ação organizacional de uma nova perspectiva.

Não é preciso partilhar das esperanças da filosofia habermasiana, ou seja, a de sujeitos livres dialogando sobre objetivos, valores e normas, visando alcançar um consenso e a partir daí construir uma sociedade justa e democrática. Contudo, há em Habermas o esforço para coordenar duas ordens da experiência, o "mundo da vida" e o "sistema", considerando o uso social da palavra. Com isso, abre-se um campo para a análise do sentido da ação, que não poderia estar no domínio do paradigma cartesiano do pensador solitário.

Habermas, ao propor sua teoria sobre a racionalidade da ação, afasta-se do paradigma da consciência, voltandose para o uso social da palavra. Como lembra McCarthy (1992):

"a resposta de Habermas à decadência do paradigma da consciência é um giro explícito ao paradigma da linguagem, não à linguagem como sistema analítico semântico, mas à linguagem em uso ou fala. Daí que desenvolve o marco categorial e as bases normativas de sua teoria social em forma de uma teoria geral da ação comunicativa" (p.448).

Recorrer a Habermas não se deve, aqui, à adoção plena de suas idéias, sobretudo quando elas se associam a um plano de fala ideal que estabeleceria, como efeito, uma ação comunicativa pura. Isso implicaria aceitar que os sujeitos em interação são capazes de decidir e argumentar sobre o sentido de seus enunciados e conquistar acordo quanto ao mesmos, tendo em vista a coordenação de ações.

Essa suposição não seria sustentável diante de uma análise cuidadosa das relações entre sujeito e linguagem. A condição de fala ideal traz consigo a noção de que o sujeito é exterior à linguagem e que pode servir-se dela como um sistema mais ou menos preestabelecido de significações. No entanto, se considerarmos que não há exterioridade entre sujeito e linguagem, e que tanto o sujeito, como a linguagem encontram-se em processo de produção através dos atos enunciativos, é preciso abandonar a miragem da compreensão plena presente na teoria da ação comunicativa.

Contudo, o recurso a Habermas deve-se a que, no contexto da teoria da ação, é ele quem se ocupa de revisar a noção de ação teleológica, ou seja, voltada a fins, que é muito valorizada no entendimento sobre o sentido da ação organizacional. E é em Habermas que o sujeito da consciência, que pensa ou que examina introspectivamente suas percepções, sensações e vivências encontra a porta de saída para um plano social e discursivo no qual se decidirá sobre o sentido da ação.

Essa saída para um plano social e discursivo é estabelecida quando se valoriza a cultura e as aprendizagens sociais para a compreensão e desenvolvimento da ação das e nas organizações. Há aí um novo posicionamento epistemológico quanto ao entendimento sobre o sentido da ação. Nesse posicionamento epistemológico

$1 \mathrm{O}$ autor refere-se à obra de Erving Goffman, The presentation of self in everyday life, publicada em 1959. 
rompem-se as dicotomias sujeito/objeto, mente/corpo, razão/sentido, eu/outro, em favor de um campo único no qual se integram as diferentes dimensões que concorrem para conferir sentido à ação. Esse campo único é um campo discursivo que atravessa o sentido da ação, seja no plano coletivo ou na singularidade do sujeito. Em outras palavras, a ação passa a ser considerada como uma realidade discursiva, ou seja, tributária de um sentido construído na linguagem.

Reencontramos aí o conceito semiótico de cultura de Geertz (1989) com a noção do "homem amarrado a teias de significados que ele mesmo teceu" (p.15). Por esse prisma, a cultura se constitui dessas teias, e analisá-la é penetrar nos modos particulares através dos quais essas teias se compõem, combinam-se e se modificam.

Assim, como sugere Thompson (1995), a vida social não é simplesmente uma questão de objetos e de fatos que ocorrem como fenômenos de um mundo natural. Ela é, também, uma questão de ações e expressões significativas, de manifestações verbais, símbolos, textos e artefatos de vários tipos e de sujeitos que se expressam através desses artefatos, procurando entender a si mesmos e aos outros pela interpretação das expressões que produzem e recebem. Em sentido mais amplo, o estudo dos fenômenos culturais pode ser pensado como o estudo do mundo sociohistórico constituído por um campo de significados.

\section{0 processo decisório: da racionalidade limitada à produção de sentido}

Desde os trabalhos pioneiros de Herbert A. Simon, produzidos na década de 1950, a teoria da ação organizacional tem se desenvolvido sistematicamente nos últimos 40 anos. Contribuições relevantes da economia, da teoria institucional, dos estudos interpretativos e da análise das redes têm sido incorporadas às concepções contemporâneas. Os estudos sobre ação organizacional integram uma comunidade extensa formada por economistas, sociólogos, historiadores, cientistas políticos, psicólogos, os quais trazem contribuições, de diferentes perspectivas não previstas nos primeiros estudos (MARCH, 1999).

A abordagem clássica da ação é construída com base no pressuposto de que ações derivam de escolhas e escolhas derivam de previsões sobre o futuro. Segundo March (1999), elementos dessa abordagem fazem parte do discurso padrão culto ocidental dos séculos XVII e XVIII, caracterizado pelo triunfo do racionalismo e do utilitarismo. O trabalho de Simon surge como um esforço de revisão desses pressupostos, pelo menos, no que concerne às decisões e ações organizacionais.

Simon (1965) desenvolve o conceito de "racionalidade limitada", confrontando as análises empíricas com padrões definidos para uma racionalidade objetiva (ou ideal). A racionalidade objetiva supõe:

- a visão panorâmica das alternativas de comportamento, antes da tomada de decisão;

- considerar todo o complexo de conseqüências que advirão de cada escolha;

- escolher uma alternativa entre todas aquelas disponíveis.

Em contrapartida, o comportamento real não alcança racionalidade objetiva em pelo menos três aspectos diferentes:

- é apenas fragmentário o conhecimento das condições que cercam a ação e a percepção das regularidades dos fenômenos e das leis que permitiriam gerar futuras conseqüências com base nos conhecimentos das circunstâncias atuais;

- a avaliação de consequiências é limitada na sua exatidão e consistência, sendo substituída pela imaginação;

- no comportamento real, apenas uma fração de todas as possíveis alternativas é levada em consideração.

O conceito de racionalidade limitada tem importantes efeitos em proposições para o funcionamento das organizações. Estas devem adequar sua estrutura e função às contingências que os processos humanos impõem. Dessa perspectiva, March e Simon (1967) sugerem que as organizações desenvolvam modelos simplificados de ação, a fim de captar e resolver os principais problemas. As simplificações apresentam características como:

- o ótimo substituído pelo satisfatório; 
- as alternativas de ação e as conseqüências da ação se revelam em sequiência, através de processos de procura;

- organizações e indivíduos desenvolvem repertórios de programas de ação, que servem como alternativas de escolha de situações repetidas;

- cada programa específico de ação envolve uma série restrita de situações e uma série restrita de conseqüências;

- cada programa de ação é suscetível de ser executado em semi-independência dos demais.

Essas proposições para o funcionamento organizacional podem ser tomadas como alternativas para estabelecer racionalidade nas contingências da racionalidade limitada. A tecnologia da informação tem aí um espaço consagrado. Ela é considerada como um substitutivo para o tratamento da variedade e da quantidade de informação que ultrapassa a capacidade humana de processamento. Como afirma Aktouf (1989):

“(...) os sistemas de informação constituem a trama nervosa da empresa, com um sistema periférico de coleta e de encaminhamento e um sistema central de memória e de tratamento. A organização é necessariamente considerada como uma entidade formal, racional, hierarquizada e compartimentalizada. $\mathrm{O}$ formalismo está associado à concepção de que a estrutura deve se adaptar sobre a base de uma lógica de informação na qual o fluxo, os canais, os emissores, os receptores, as memórias (...) impõem ordem, seqüências e tipos particulares de interação" (p.235).

Em outras palavras, a racionalidade é reificada a partir da criação de modelos capazes de compensar as dificuldades provenientes das limitações humanas e a partir do domínio do tratamento da informação que, apoiado na tecnologia, confere renovadas esperanças aos ideais de modernidade.

Contudo, isso não impede que a ação organizacional, no plano individual ou coletivo, tome seu próprio curso, ou seja, siga uma lógica própria que ainda não é totalmente apreensível, nem mesmo com a sofisticação dos modelos administrativos desenvolvidos desde o conceito de racionalidade limitada.

Simon (1989), numa reflexão sobre os limites da racionalidade e as relações entre a razão, a intuição e a emoção explora a idéia de que no domínio do raciocínio "não há conclusões sem premissas". Ou seja, os processos de raciocínio captam informações simbólicas para produzirem resultados simbólicos:

As informações iniciais são axiomas que não derivam da lógica, mas são apenas induzidos a partir das observações empíricas ou, mais simplesmente, pressupostos. Além disso, são também impostos os processos que transformam as informações iniciais em resultados (regras de inferência), pelo que não provém da razão. Os axiomas e as regras de inferência constituem, em conjunto, o fulcro onde se assenta a alavanca do raciocínio (...) A razão funciona, por conseguinte, só depois de ter recebido um conjunto adequado de informações iniciais ou premissas. Se a razão for aplicada à descoberta e à escolha de percursos de ação, então, essas informações que recolhemos incluem, pelo menos, um conjunto de proposições com a partícula deve, ou valores a serem alcançados, e um conjunto com a partícula é, ou fatos sobre o universo em que a ação vai ser concretizada. Qualquer tentativa para justificar o deve e o é através da lógica conduzirá simplesmente a um retorno até novos deves e és postulados de forma semelhante (SIMON, 1989, p.15-16).

Isso significa que mesmo que um modelo para o funcionamento organizacional ou para o tratamento da informação se torne capaz de assumir procedimentos racionais nas contingências da racionalidade limitada, existe, como condição necessária, uma etapa anterior, os axiomas, que derivam de pressupostos exteriores à redução lógica. No domínio da definição de axiomas concorrem variáveis associadas aos valores. Estamos, assim, mais uma vez, no campo da cultura e, por que não, no campo do sentido e de sua produção.

Além disso, a noção de que a condição de racionalidade limitada pode ser compensada por um tratamento adequado da informação, ou seja, ordenado e sequiencial, é também interrogada a partir de estudos como o de March e Olsen (1976) que rejeitam a hipótese da aprendizagem como uma simples adaptação racional. Isso significa que diante das limitações humanas em considerar a multiplicidade de possibilidades na previsão das 
ações, existe como alternativa a hipótese de que a ação desenvolve-se a partir do comportamento (individual e coletivo) racional e adaptável em face da experiência.

O que se interroga nessa abordagem são as limitações da aprendizagem a partir da experiência. A experiência, segundo March e Olsen (1976), requer interpretação e as aprendizagens ocorrem em condições de ambigüidade:

"Consideramos que organizações adaptam seu comportamento a partir de sua experiência, mas que a experiência requer interpretação. Elas aprendem em condições nas quais os objetivos (e, portanto, 'sucesso' e 'fracasso') são ambíguos e conflitantes, nas quais o que aconteceu não está claro e nas quais a causalidade dos eventos é difícil de estabelecer. As pessoas nas organizações chegam a acreditar no que aconteceu, no porquê tal evento aconteceu e se foi positivo; mas o processo através do qual essas crenças são estabelecidas em face de um tão problemático mundo 'objetivo' afeta sistematicamente o que é aprendido" (p.55).

March e Olsen (1976) propõem o exame das condições de aprendizagem em situações de ambigüidade. Os autores estendem um modelo de aprendizagem apropriado a um universo no qual se supõe preferências claras e resultados precisos para as situações nas quais é difícil determinar o que ocorreu, por que ocorreu, se foi favorável e se o passado é comparável ao presente. Consideram que a aprendizagem deve incluir quatro grandes categorias de idéias:

- idéias sobre exposição à informação, memória e evocação - as organizações têm estruturas de comunicação através das quais a informação é transmitida. O resultado disso é que indivíduos diferentes e partes da organização "vêem" mundos diferentes. As ocasiões de busca de informação, assim como a definição sobre onde a informação será buscada variam. $\mathrm{O}$ modo como funciona a memória organizacional afeta consideravelmente o padrão de crenças existentes na organização;

- idéias sobre incentivos à aprendizagem - nas situações em que não há clareza quanto às informações ou aos resultados esperados, muitas interpretações alternativas são possíveis. A questão passa a ser os motivos (incentivos) que levam uma pessoa em particular, ou parte da organização, a selecionar uma interpretação em detrimento de outras;

- idéias sobre a estrutura das crenças - o desenvolvimento de crenças em condições de ambigüidade acentua a importância das estruturas cognitivas e valorizadoras preexistentes. A compreensão dos eventos está conectada a "compreensões" prévias, à compreensão de outras pessoas e aos laços sociais de amizade e confiança;

- idéias sobre o microdesenvolvimento das crenças - crenças, assim como decisões, são sensíveis aos detalhes do tempo, à ordem e ao contexto da informação.

Em síntese, o que foi anteriormente esquematizado é um percurso situado no contexto dos estudos sobre o processo decisório, que começa com a crítica às possibilidades humanas de onisciência a serviço da racionalidade e prossegue com:

- a proposição do conceito de racionalidade limitada;

- a adequação de modelos administrativos à idéia de racionalidade limitada;

- uma visão crítica quanto a esses modelos organizacionais, desde uma análise das limitações das possibilidades de aprendizagem através da experiência;

- a noção de que, no contexto dos estudos sobre processo de decisão, a investigação precisa voltar-se para o modo como é estabelecido o conjunto de crenças individuais e coletivas que tem efeito na ação.

À medida que a investigação sobre a ação desloca a atenção dos aspectos supostamente objetivos - como o cálculo racional de possibilidades de ação ou o aprimoramento de modelos para o tratamento da informação para o modo através do qual se estabelecem as crenças que justificam a ação, um novo posicionamento epistemológico é estabelecido no domínio dos estudos sobre a ação organizacional. 
Os estudos sobre o processo decisório apresentam no seu desenvolvimento análises sobre o sentido e sua produção. Quando se investiga as crenças subjacentes à ação, não é de outra coisa que se fala, senão do sentido e sua produção. Portanto, estamos mais uma vez no campo do discurso, pois é esse o campo possível de investigação sobre o sentido.

Para tanto, Weick (1995) explora o conceito de sensemaking. Weick trabalha com a questão da percepção e interpretação da informação pelos sujeitos em contextos socioculturais definidos. Trata-se de compreender por que, coletivamente, evidências empíricas e informações são negligenciadas em favor de algum sentido privilegiado que corresponda a redes estabelecidas de sentido histórico, cultural e social.

Nas organizações, algumas situações se definem como oportunidades de ambigüidade e incerteza para o processo de sensemaking. São situações como a de:

- acúmulo de informações, que acaba resultando em omissão, filtragem e seleção;

- interdependência de diferentes elementos que interagem numa grande variedade de combinações, gerando complexidade que, quanto maior, tende a ser reduzida a esquemas rotineiros e habituais; e de

- turbulência do ambiente, definida como uma combinação de instabilidade (frequiência da mudança) e caráter aleatório (frequiência e direção da mudança), fazendo com que as pessoas adotem esquemas explicativos compatíveis com aquilo que conhecem melhor, ou seja, com o que é habitualmente praticado (WEICK, 1995).

Sensemaking refere-se ao processo de construção das situações, dos problemas, dos fatos a serem compreendidos, interpretados ou administrados. Esse processo está baseado nas relações entre três elementos: um esquema de referências, um elemento evocativo e uma conexão:

"(...) o processo de sensemaking pretende incluir a construção e a colocação em destaque das entrelinhas que são interpretadas, assim como a revisão dessas interpretações, baseadas em ações e suas conseqüências. Sensemaking refere-se à autoria, assim como à interpretação e à descoberta" (WEICK, 1995, p.8).

Valendo-se de uma expressão de Rorty (1989, cap.1), Weick (1995) diz que as pessoas produzem sentido (compõem o sensemaking) a partir de diferentes "vocabulários":

"Buscam palavras dos vocabulários da sociedade e produzem sentido, usando ideologia. Buscam palavras dos vocabulários das organizações e produzem sentido usando controles de terceira ordem. Buscam palavras dos vocabulários de ocupações e profissões e produzem sentido, usando paradigmas. Buscam palavras dos vocabulários da atividade e produzem sentido, usando teorias da ação. Buscam palavras dos vocabulários dos antepassados e produzem sentido, usando tradição. Buscam palavras dos vocabulários da sequiência e experiência e fazem sentido usando narrativas(...)"(p.106).

Vocabulários constituem os elementos que compõe o sensemaking, em sua substância. Esses vocabulários podem ser compreendidos através de categorias como (WEICK, 1995, cap.5):

- ideologia - vocabulários da sociedade: ideologias são definidas como um conjunto compartilhado de crenças, valores e normas coerentemente inter-relacionadas, que mantém algumas pessoas unidas e as ajuda a dar sentido a suas realidades. Desse modo, ideologias combinam crenças sobre relações de causa e efeito, preferências por determinados resultados e expectativas quanto aos comportamentos considerados adequados ou inadequados. Nas organizações, ideologias podem também agir como filtros para a complexidade e diversidade de informações, simplificando, assim, o universo perceptivo. Como elemento constituinte do sensemaking, as ideologias são tomadas de modo mais fragmentário do que ocorre nas teorias macroexplicativas da sociedade e das instituições. Considera-se que os sujeitos atribuem sentidos diferentes aos conteúdos das macroideologias, que, por sua vez, nunca são transmitidas e reproduzidas de modo idêntico; 
- controles de terceira ordem - vocabulários da organização: controles de terceira ordem é uma expressão proposta por Perrow (1986). As organizações operam com três formas de controle, que são os "controles de primeira ordem", através da supervisão direta; os "controles de segunda ordem", através de programas e rotinas; e os "controles de terceira ordem", que consistem em pressupostos e definições tácitos. Os controles de terceira ordem são chamados de "controles de premissa" porque influenciam as premissas que as pessoas usam quando diagnosticam situações e tomam decisões. Os controles de premissa implicam algo que participa no princípio do processo de sensemaking, influenciando todas as etapas subseqüentes. Esse tipo de controle tende a influenciar de modo mais evidente as atividades não rotineiras;

- paradigmas - vocabulários do trabalho: paradigmas são como ideologias e premissas, no sentido de que todos os três são termos que trazem uma heurística simplificadora. O aspecto distintivo dos paradigmas é que se tornam sistemas auto-suficientes, capazes de oferecer realidades alternativas. Paradigmas compreendem um conjunto de pressupostos implícitos sobre a variedade de aspectos que compõem a realidade, como agem e se combinam e, também, sobre como podem ser conhecidos. Os paradigmas são transmitidos através das formas particulares de agir e pensar, dos exemplos de como lidar com situações concretas. Desse modo, estão mais próximos das culturas do que dos sistemas filosóficos. Em suma, constituem um repertório conceitual, empregado na busca de solução dos problemas organizacionais;

- teorias da ação - vocabulários do enfrentamento: as teorias da ação partem do pressuposto de que as pessoas nas organizações constroem conhecimento à medida que respondem às situações e aos problemas com que se defrontam. A partir das experiências de ensaio e erro, o território da ação é mapeado e se estabelecem inferências de relações de causa e efeito. Assim, são criadas abstrações que têm efeitos no sensemaking. Afirmações sobre implicações, afirmações contendo asserções do tipo "se então" e afirmações que descrevem estruturas do tipo "meios e fins" apresentam conteúdo que pode ser associado com teorias da ação. Uma distinção importante nas teorias da ação, com relevantes efeitos na sua investigação é se elas efetivamente estão associadas à ação ou se são apenas declaradas ou adotadas pelo sujeito.

- tradição - vocabulário dos predecessores: a tradição se refere a algo que foi criado, realizado ou acreditado no passado, ou que se acredita tenha existido ou se realizado no passado e que tem sido ou está sendo transmitido ou foi transmitido de uma geração para a seguinte. Objetos são transmitidos, assim como imagens e crenças. Da ação, só são transmitidas imagens ou crenças que a requerem, recomendam, permitem ou proíbem. Ela mesma (a ação) não pode ser transmitida. Um aspecto bizarro na tradição é que a ação humana concreta, o know-how implícito na prática persiste e é transmitido apenas na condição de tornar-se simbólico. Assim, a ação, para preservar sua forma, deve se modificar para depois ser reconstituída. Essa complexa transformação significa que os conteúdos das imagens usadas para representar a ação são cruciais porque determinam o que será perpetuado. Imagens do know-how, receitas, roteiros, práticas (hábitos) e heurísticas representam simbolismos do trabalho, os quais possibilitam a transmissão através das gerações. Tradições, assim como paradigmas, têm modelos e depositários, histórias e contadores de histórias. As ações são fugazes, mas as histórias sobre a ação não o são. Se as organizações são formas sociais que se distinguem por sua capacidade de coordenação da ação e se o caráter distintivo dessas formas desaparece quando a ação se realiza, então, precisamos nos preocupar com o que persiste, já que as ações são apenas evanescentes. Esses elementos que persistem estão na base do sensemaking;

- histórias - vocabulários da sequiência de experiências: a importância das histórias está associada à noção de que as pessoas pensam mais de um modo narrativo do que argumentativo ou paradigmático. Considerando a propensão humana à indução generalizadora, experiências importantes freqüentemente se tornarão a base empírica para práticas, provérbios e outro guias de conduta. Assim, contar histórias sobre experiências notáveis é um dos modos pelos quais as pessoas buscam tornar o esperado inesperado e, assim, administrável. A narração é um modo de descrição que transforma eventos em fatos históricos; mas não se deve pensar que a narração é uma duplicação da experiência. As histórias organizam e filtram a experiência. As histórias:

- ajudam a compreensão pela integração com os elementos conhecidos de um evento, outros apenas conjeturais;

- sugerem uma ordem causal para eventos que originalmente são percebidos como não relacionados; 
- capacitam as pessoas a falar sobre coisas ausentes e conectá-las com o presente, na busca de significados;

- permitem às pessoas reconstruir eventos complexos, por serem mnemônicas;

- são capazes de guiar a ação antes que rotinas sejam formuladas, podendo, assim, enriquecê-las;

- permitem às pessoas construir uma base de dados da experiência, a partir da qual possam inferir como as coisas funcionam;

- transmitem e reforçam controles de terceira ordem, propagando valores e significados compartilhados.

Com isso, encontramos encaminhamentos para a teoria da decisão que nitidamente se afastam do controle positivo da informação. As formas de construção, interpretação e transmissão ganham ênfase. Assim, é no campo da linguagem e em seus limites que a decisão traça seus contornos.

\section{Considerações finais: finalidade ou linguagem como paradigmas para a ação organizacional}

Apresentamos aqui dois caminhos teóricos com o argumento de que, embora paralelos - já que correspondem a distintas derivações disciplinares -, são convergentes, pois encontram em seu desenvolvimento um paradigma comum.

Entre Weber e Habermas verificamos um deslocamento da noção de sujeito que age conforme sua consciência para uma noção de sujeito social, cuja ação está associada às interações e relações discursivas que estabelece.

Entre a noção de racionalidade limitada de Simon e o conceito de sensemaking em Weick, há o deslocamento de um modelo para otimização das representações provenientes da realidade para uma concepção de realidade social e discursivamente construída e não apenas representada.

Assim, seja do ponto de vista do agente da ação (o sujeito) ou do ponto de vista do objeto sobre o qual incide a ação, encontramos conceitos que se afastam das cisões sujeito/objeto em favor do estabelecimento de um campo epistêmico, no qual sujeito e objeto pertencem a uma mesma realidade discursiva.

Em síntese, identificamos duas abordagens para a compreensão do sentido da ação organizacional:

- abordagem objetivista ou paradigma da finalidade - na qual o sentido da ação é sua finalidade teleológica. O agente da ação é o ator racional que age no isolamento de sua reflexão e consciência. A ação ou decisão é regulada pelas possibilidades de racionalidade. Nessa abordagem, sujeito e objeto pertencem a campos diferentes. O objeto é exterior A ação se dá quando o sujeito imprime ao objeto os efeitos de sua razão ou vontade;

- abordagem discursiva ou paradigma da linguagem - a ação é resultado dos efeitos na linguagem produzidos por sujeitos em interação. A ação é um efeito de sentido que se produz na linguagem. O agente da ação é um sujeito em relação, ora singular, ora coletivo, emaranhado numa teia de significados social e culturalmente construídos. Nessa abordagem, sujeito e objeto estão na mesma dimensão, já que ambos são efeitos de redes de significados.

Como já ressaltado no início deste artigo, os argumentos aqui desenvolvidos ganham lugar quando se evidencia o papel-chave desempenhado pela cultura e por aprendizagens sociais em processos organizacionais. Ação e decisão em organizações têm sido cada vez mais compreendidas como efeitos de regras institucionais, adequação social, imitação, ideologia, busca de identidade e legitimidade.

Considerando a abordagem discursiva ou o paradigma da linguagem como mais explicativos do que ocorre hoje nas organizações, torna-se um desafio investigar as configurações, contingências, dimensões e a estrutura tanto do sujeito quanto das realidades discursivamente construídas. Dessa perspectiva, há um extenso trabalho a ser desenvolvido no campo das relações entre trabalho e linguagem; processo decisório e construções discursivas; interpretação e narrativas. Com isso, ganham ênfase na agenda dos estudos organizacionais, temas 
como os estudos sobre a cognição, a filosofia da linguagem, a psicanálise, a sociologia interacionista e a semiótica. 


\section{Referências bibliográficas}

AKTOUF, O. Le management entre tradition et renouvellement. Quebec: Gaëtan Morin, 1989.

GEERTZ, C. A interpretação das culturas. Rio de Janeiro: Guanabara Koogan, 1989.

FREITAG, B. A teoria crítica: ontem e hoje. São Paulo: Brasiliense, 1993.

_; ROUANET, S. P. (Org.). Habermas. São Paulo: Ática, 1993. (Coleção Grandes Cientistas Sociais).

HABERM AS, J. The theory of communicative action. Reason and the rationalization of society. Tradução de Thomas M cCarthy. Cambridge, UK: Polity Press/Blackwell, 1995. v.1 e 2.

MARCH, J. The pursuit of organizational intelligence. Malden, MA: Blackwell, 1999.

; OLSEN, J. Ambiguity and choice in organizations. Bergen: Universitetsforlaget, 1976.

; SIM ON, H. Teoria das organizações. Rio de Janeiro: FGV, 1967.

MCCARTHY, T. La teoría crítica de Jürgen Habermas. Madrid: Tecnos, 1992.

PERROW, C. Complex organizations. Nova lorque: Basic Books, 1986.

PHARO, P. Le sens de l'action et la compréhension d'autrui. Paris: Harmattan, 1993.

PIZZI, J. Ética do discurso: a racionalidade ético-comunicativa. Porto Alegre: Edipucrs, 1994. (Coleção Filosofia).

RORTY, R. Contingency, irony and solidarity. Cambridge, UK: Cambridge University Press, 1989.

SIM ON, H. Comportamento administrativo. Rio de Janeiro: FGV, 1965.

Sciences of the artificial. Cambridge, MA: MIT Press, 1969.

. A razão nas coisas humanas. Lisboa:Gradiva, 1989.

THOM PSON, J. Ideologia e cultura moderna. Rio de Janeiro: Vozes, 1995.

WEICK, K. Sensemaking in organizations. Londres: Sage, 1995. 